\title{
Detection of oviposition-deterring larval tracks in Chrysopa oculata and Chrysopa perla (Neuroptera: Chrysopidae)
}

\author{
ZDENĚK RŮŽIČKA \\ Institute of Entomology, Biology Centre of Academy of Sciences, Branišovská 31, 37005 České Budějovice, Czech Republic; \\ e-mail: ruzicka@entu.cas.cz
}

Key words. Neuroptera, Chrysopidae, Chrysopa oculata, C. perla, antennae, cannibalism, palpi, pheromones, predator, semiochemical, sensory ablation

\begin{abstract}
We investigated the ability of females of the aphidophagous chrysopids Chrysopa oculata and Chrysopa perla to distinguish clean substrates from substrates with tracks of chrysopid first instars after ablation of various sensory organs potentially involved in the detection of oviposition-deterring semiochemicals (ODSCs). Also studied were effects of storage time on the degree of oviposition deterrence of substrates contaminated by larvae and by extracts of ODSC in intact females. C. oculata and C. perla laid significantly fewer eggs on substrates with conspecific larval tracks than on simultaneously provided clean substrates. Females of both chrysopids could perceive ODSCs solely through sense organs on the head. The oviposition of each species was significantly lower on contaminated than on clean substrates when any kind of sense organ on the head was completely removed, i.e. antennae, maxillary palpi, or labial palpi. C. oculata could still effectively differentiate substrates after ablation of both maxillary and labial palpi, indicating possible detection of volatiles via the antennae during flight. Only if all three pairs of sensory appendages were removed did females lay similar numbers of eggs on both substrates. In contrast, $C$. perla laid similar numbers of eggs on clean substrates and substrates with either conspecific or $C$. oculata larval tracks when maxillary and labial palpi were removed. Substrates with tracks of first instars of $C$. perla deterred $C$. oculata from oviposition after one year and conspecific females after 1.5 years from contamination. Both species laid significantly fewer eggs on substrates with tracks of $C$. oculata first instars than on clean substrates even after three years. Tracks of $C$. oculata third instars did not deter conspecific females more than tracks of first instars. ODSCs from tracks were easily extracted with water. Thus, precipitation is likely to reduce deterrent effects of contaminated plants. Chloroform extract from C. oculata first instars strongly deterred conspecific females from oviposition. Even after 725 days of storage, we found no statistically significant decline in the effect. The extract could be used to redirect egg laying from constructional parts of rearing cages to exchangeable oviposition substrates in mass rearing of chrysopids used for biological control. The hexane extract of third instars was inactive.
\end{abstract}

\section{INTRODUCTION}

Chrysopids are common predators of phytophagous mites and various insects (McEwen et al., 2001). Some species are highly polyphagous and considered effective biological control agents of lepidopteran pests in open fields (Ridgway \& Jones, 1969). Many chrysopids specialise on aphids in the larval stage, or in both larval and adult stages. Eggs and larvae of several mass-reared species have been effectively deployed for aphid control in greenhouses (Benuzzi et al., 1991; Ravensberg, 1992). Although the use of these beneficial species for plant protection has resulted in massive reductions of pesticide use in some cases (Hokkanen, 1997), unexplained failures have also been frequent (Senior \& McEwen, 2001). In addition to other factors, deterrent effects of chrysopid larvae on conspecific and heterospecific females and larvae have likely contributed to the undesirable dispersal of predators from release sites and declines in expected efficiency.

The first evidence of chemically mediated inhibition of oviposition emerged from experiments with the golden-eye lacewing, Chrysopa oculata Say (Růžička, 1994). When substrates with tracks of conspecific larvae were provided, females strongly avoided ovipositing on them, preferring to lay eggs on substrates without tracks. Oviposition-deterring semiochemicals (ODSCs) from larval tracks have since been shown to influence egg distribution in other chrysopid species (Růžička, 1996), in coccinellids (Růžička, 1997b), and in aphidophagous gall midges (Růžička \& Havelka, 1998). In contrast to tracks of conspecific larvae, the presence of eggs did not deter chrysopid and coccinellid females from ovipositing (Růžička, 1994; Fréchette et al., 2006). Both chrysopid and coccinellid larvae use the tip of the abdomen as a highly effective pseudopod, especially while traversing the abaxial surfaces of leaves. ODSCs are present in the remains of adhesive secretions used to fix the abdominal discs of larvae to the plant surface (Růžička, 1994; Laubertie et al., 2006).

Insect females perceive ODSCs via olfactory or contact chemoreceptors located on various sense organs. The cherry fruit fly, Rhagoletis cerasi (L.) (Diptera: Tephritidae), detects the relatively stable oviposition-deterring pheromone of conspecifics through tarsal contact receptors (Hurter et al., 1976; Städler et al., 1994). Pieris brassicae (L.) and Pieris rapae (L.) (Lepidoptera: Pieridae) use tarsal, antennal, and abdominal chemoreceptors to detect non-volatile and volatile components of conspecific ODSCs (Klijustra \& Roesingh, 1986; Schoonhoven, 
1990). In contrast, Ceutorhynchus assimilis (Paykull) (Coleoptera: Curculionidae) uses contact gustatory receptors on the antennae (Ferguson et al., 1999) and Monochamus alternatus Hope (Coleoptera: Cerambycidae) uses maxillary and labial palpi (Anbutsu \& Togashi, 2000, 2001). Parasitoids frequently employ antennae but may also use chemoreceptors on the ovipositor to assess the presence of pheromone markers on the host (van Lenteren, 1972). Aphidophagous coccinellids appear to perceive conspecific and heterospecific larval tracks via maxillary palpi (Růžička, 2003).

Chrysopid females have various sensillae on different body parts, especially on appendages and the tip of the abdomen (Bitsch, 1984). Chemosensillae are particularly numerous on the antennae, and previous studies have concentrated on antennal perception of volatiles. Artificial diets and volatile synomone compounds of prey host plants have been shown to attract some species (Hagen \& Tassan, 1966; van Emden \& Hagen, 1976; Hagen, 1986). Electroantennogram (EAG) studies have demonstrated a significant response by Chrysoperla carnea (Stephens) to 2-phenylethanol emitted from the host plant of the prey, and traps baited with this compound attracted mostly females (Zhu et al., 2005). Other EAG studies with Chrysopa septempunctata (Wesmael), Chrysopa sinica (Tjeder), and C. carnea showed that adults could differentiate between volatiles from different prey host plants (Han \& Chen, 2002a, b; Reddy, 2002). Wind tunnel experiments even revealed a preference for certain Brassica host plants by $C$. carnea females, but not males (Reddy et al., 2004) and responses to extracts of corn leaves also differed between males and females (Zhu et al., 1999).

Adult chrysopids have shown attraction to components of aphid sex pheromones in an antennogram study (Boo et al., 1998) and C. carnea responds strongly to (E)-betafarnesene, the aphid alarm pheromone (Zhu et al., 1999). Whereas single olfactory sensillae of $C$. carnea react to both 2-phenylethanol and aphid sex pheromone components, those of $C$. oculata respond only to sex pheromone components (Zhu et al., 2005). Both sexes of C. carnea respond to a mixture of two major components of the pheromone of Plutella xylostella (L.) in an Y-tube olfactometer, but not to the individual compounds (Reddy et al., 2002). These studies indicate species-specific responses to prey-associated semiochemicals.

Chrysopids perceive conspecific semiochemicals also via the antennae. In gas chromatographic-electroantennographic detection (GC-EAD) experiments, males and females of $C$. oculata reacted to four compounds from the abdominal cuticle of males that are absent in females (Chauhan et al., 2004; Zhang et al., 2004). Both males and females were strongly attracted to iridodial, a malespecific compound of $C$. oculata, and aggregated near lures of this compound in nature, suggesting the possibility it could be used to increase oviposition in targeted fields (Chauhan et al., 2007). Iridodial also attracted males of another species, Chrysopa septempunctata (Zhang et al., 2006), and the pheromone retained activity for more than two months. Several other substances also attracted males of different chrysopid species but not females (Hooper et. al., 2002). The detection of defensive secretions of $C$. carnea was reported to occur via antennae. Field tests confirmed deterrent effects of the major compound, a tridecene. The avoidance behaviour of predatory ants, observed in tests with the synthetic tridecene, also suggested a defensive function of this substance (Zhu et al., 2000).

Although chrysopids use antennae for perception of some semiochemicals of conspecific origin, the location of sensillae that enable females to detect ODSCs has not been investigated to date. In a comparative study with four chrysopid species, the strongest response of females to tracks of conspecific first instars was in C. oculata and the lowest in C. perla (Růžička, 1998). Therefore, the present study was undertaken to identify organs for ODSC perception in C. oculata and C. perla. An associated objective was to compare the persistence of intraand interspecific effects of ODSCs on females. Because chloroform extracts of larvae and larval tracks had similar oviposition-deterring effects (Růžička, 1994), the persistence of the extract was studied for its possible use in mass rearing of chrysopids in biological control programs. If stable, the extract could be employed in rearing containers to divert egg laying from structural elements to exchangeable oviposition substrates. The solubility of ODSCs in water was investigated with respect to their persistence on plants.

\section{MATERIAL AND METHODS}

\section{Insects}

Experiments were made with two eurytopic chrysopids, the Nearctic C. oculata (origin: Nova Scotia, Canada, collected in 1989) and the Palaearctic C. perla (origin: South Bohemia, Czech Republic, collected in 1992). Both species have been reared continuously in the laboratory since collection at $24 \pm$ $2^{\circ} \mathrm{C}$ and $18 \mathrm{~L}: 6 \mathrm{D}$ photo-phase. Larvae and adults of both species were fed with the pea aphid $A$. pisum. Adults were also supplied with tap water and a complementary diet containing yeast hydrolysate, sucrose, and water. Adult chrysopids were kept in nylon cages $40 \times 40 \times 40 \mathrm{~cm}, 300-400$ insects per cage. Approximately 50 eggs were collected from each cage three times a week and placed on folded paper strips on the bottom of $0.5-\mathrm{L}$ jars. The inner side of the walls of jars were coated with fluon (polytetrafluoroethylene dispersion in water, SigmaAldrich Chemie $\mathrm{GmbH}$ ) applied to prevent the escape of eclosing larvae. Aphids were added prior to eclosion and on each subsequent day. At the second instar, 25 larvae of similar size were selected for rearing in each jar. Jars were then cleaned daily until pupation and adults were released into cages immediately after emergence.

\section{Experimental design}

The oviposition of C. oculata and C. perla was studied in choice tests in which clean and contaminated substrates were presented simultaneously. Experimental designs of tests were adopted from previous studies (Růžička, 1998; 2001b) and modified for individual experiments as needed. Cylindrical cages $(19.5 \mathrm{~cm}$ diameter $\times 10 \mathrm{~cm}$ height) were made from firm netting with glass tops and bottoms. Ten chrysopid females, each 10-20 days old, were placed in each cage without males 
TABLE 1. Summary of sense organs ablated in various oviposition deterrence experiments with two Chrysopa spp.

\begin{tabular}{lccc}
\hline Ablated organ(s) & Abbreviation for test & Tests with Chrysopa oculata & Tests with Chrysopa perla \\
\hline None* & $\mathrm{BT}$ & + & + \\
None & 0 & + & + \\
One antenna & $1 \mathrm{a}$ & + & - \\
Antennae** & $2 \mathrm{ac}$ & + & + \\
Antennae & $2 \mathrm{a}$ & + & + \\
Labial palpi & $2 \mathrm{l}$ & + & + \\
Maxillary palpi & $2 \mathrm{~m}$ & + & - \\
Antennae, maxillary palpi & $2 \mathrm{am}$ & + & + \\
Labial palpi, maxillary palpi & $2 \mathrm{~lm}$ & + & - \\
Antennae, labial palpi & $2 \mathrm{al}$ & + & - \\
Antennae, labial palpi, maxillary palpi & $2 \mathrm{alm}$ & + & + \\
One leg of the second pair** & $1 \mathrm{Lc}$ & + & + \\
\hline
\end{tabular}

*Clean substrates only; ${ }^{* *}$ organs were cut off with a pair of Wecker scissors. Organs were extirpated with a fine pair of forceps in other tests.

but with a surfeit of $A$. pisum. Tap water and the complementary diet were presented in two small plastic dishes, soaked in tampons. Tests were carried out at $24 \pm 2^{\circ} \mathrm{C}$ and $18 \mathrm{~L}: 6 \mathrm{D}$ photophase. Each test lasted $20 \mathrm{~h}$ and was replicated 10 times (in some cases, 5). The light source was white fluorescent tubes.

\section{Assessment of sensory organs}

The responses of intact females to substrates with tracks of larvae were compared to those of females deprived of different sense organs by surgical removal $2-3 \mathrm{~h}$ prior to testing.

Oviposition substrates consisted of four squares of dark blue paper $50 \times 50 \mathrm{~mm}$ fixed to the underside of the cage lid with narrow strips of adhesive tape. Two substrates were clean and two had fresh tracks of larvae. Each square of contaminated substrate was exposed to 10 conspecific first instars on the bottom of a glass Petri dish $(9 \mathrm{~cm}$ diameter) for $4 \mathrm{~h}$ prior to the test. The inner side of the wall of the dish was coated with fluon paint to retain the larvae. Substrates of the same kind were located in opposite corners of a hypothetical square, $110 \times 110$ $\mathrm{mm}$. The distance between adjacent squares was $10 \mathrm{~mm}$. Egg numbers on both kinds of substrates were compared after $20 \mathrm{~h}$ exposure to chrysopid females.

Intact females were used in the blank test (BT), with two pairs of clean squares, and in the control choice test (0), with two clean and two contaminated squares (Table 1). The BT was undertaken to test whether oviposition differed between locations. In other tests, either one or both organs of each type were amputated. In addition, pairs of different organs were simultaneously ablated. All segments of each organ were removed under a binocular microscope. The leg was cut away in the middle of the femur.

Because of differences in perception of ODSCs by C. oculata and C. perla (see Results), a complementary choice test was performed with $C$. perla females deprived of both kinds of palpi using substrates contaminated by $C$. oculata larvae. To verify the data of the original test with $C$. oculata females without both kinds of palpi and with substrates contaminated by conspecific larvae (test $21 \mathrm{~m}$; see Table 1 for test designations), the same test was repeated.

\section{Persistence of larval tracks}

The persistence of intra- and interspecific ovipositiondeterring effects of tracks of $C$. oculata and C. perla larvae was studied in standard choice tests. Substrates were strips of printer paper $4 \times 20 \mathrm{~cm}$, folded every $1 \mathrm{~cm}$ to a total length of $13 \mathrm{~cm}$. Contaminated substrates were exposed in pairs to either $40 \mathrm{C}$. oculata or 40 C. perla first instars in glass Petri dishes, $18.5 \mathrm{~cm}$ in diameter, coated with fluon paint on the inner side of the wall. Ten clean and ten contaminated substrates were prepared simultaneously for each period of storage and then stored separately at room temperature. The substrates were used only once after either $1,5,10,30180,360,540,720$, and 1100 days of storage. In each test, one clean and one contaminated substrate were fixed parallel to the cage lid, $25 \mathrm{~mm}$ apart. Two clean substrates were provided for oviposition in blank tests.

\section{Effect of larval age and solubility of ODSCs}

The oviposition-deterring effects of tracks of first and third instar C. oculata were compared. In addition, the solubility and persistence of ODSCs in water, chloroform and hexane were studied in choice tests.

The oviposition substrates comprised two clean and two contaminated round filter papers $(5.5 \mathrm{~cm}$ diameter $)$. The arrangement of substrates on cage lids was the same as in experiments with squares of dark blue paper. Contaminated substrates were soaked with one of the extracts; clean substrates were treated with an equal volume of corresponding solvent. In tests with fresh chloroform extract of larvae, two strips of folded filter paper were provided for oviposition as in the experiments on the persistence of larval tracks.

To compare the deterrent effects of tracks of first and third instars of $C$. oculata, eight filter paper substrates were exposed either to 50 first instars or to 40 third instars on the bottom of a Petri dish, $18.5 \mathrm{~cm}$ in diameter.

To obtain a water extract of ODSCs from tracks, 100-150 first instars were placed in a 22-ml glass vial for $24 \mathrm{~h}$, and larval tracks on the glass were then extracted with distilled water for $10 \mathrm{~min}$. The procedure was repeated on three consecutive days using a new vial on each occasion. Fresh extract was used for contamination of substrates in five replicates. In another five replicates, substrates were soaked with an extract stored at $-32^{\circ} \mathrm{C}$ for 30 days. A total volume of $0.5 \mathrm{ml}$ of water extract was applied to each substrate. Tests were initiated several hours after contamination, once substrates had dried. The volume of water extract applied to each $\mathrm{cm}^{2}$ of substrate corresponded to the tracks left by 0.7 larvae.

To obtain a chloroform extract, groups of 100-340 larvae were extracted for 2 min each. With the exception of the first experiment with fresh chloroform extract, the extract was stored first at $-30^{\circ} \mathrm{C}$ and later at room temperature. The first test was performed with chloroform extract kept for 120 days at $-30^{\circ} \mathrm{C}$ and then for 10 days at room temperature. The second test was performed with the extract kept for 120 days at $-30^{\circ} \mathrm{C}$ and then for 630 days at room temperature. The volume of the extract applied to each $\mathrm{cm}^{2}$ of substrate corresponded to 0.3 extracted larvae. 
To obtain a hexane extract of larvae, 100 third instars were extracted in $3 \mathrm{ml}$ of solvent for $2 \mathrm{~min}$. The total volume of 2.5 $\mathrm{ml}$ of clear hexane extract was applied on 20 substrates. A small fraction of heavier, brownish fluid was not used. The volume of hexane extract applied to each $\mathrm{cm}^{2}$ of substrate corresponded to 0.15 extracted larvae.

\section{Data analysis}

The differences between numbers of eggs laid on treated vs. untreated substrates within choice tests were evaluated using the non-parametric Wilcoxon signed paired-sample test. Differences between tests in the percentage of eggs laid per contaminated substrate were analysed by Student's t-test following arcsine transformation.

\section{RESULTS}

\section{Sensory organs}

Intact females of $C$. oculata and $C$. perla laid similar numbers of eggs on pairs of clean paper substrates in blank tests $(P=0.557$ and $P=0.652)$. The total numbers of eggs laid by both species in blank tests were also similar $(P=0.167)$.

In choice tests with intact females $(0)$, both species laid significantly lower numbers of eggs on substrates with fresh tracks of conspecific larvae than on clean substrates $(P=0.002)$. Although the total numbers of eggs laid by both species on paper substrates were similar $(P=0.229)$, C. oculata laid a lower proportion of eggs on contaminated substrates than did C. perla $(P<0.0001)$.

The oviposition of $C$. oculata females remained significantly lower on substrates with tracks than on clean paper when one antenna $(P=0.002)$ or both antennae were ablated (test $2 \mathrm{a}, P=0.002$; test $2 \mathrm{ac}, P=0.006$ ). Similarly, the oviposition on contaminated substrates remained lower after removal of one leg of the second pair $(P=$ $0.002)$, labial palpi $(P=0.002)$, maxillary palpi $(P=$ $0.002)$, antennae and labial palpi $(P=0.004)$, or antennae and maxillary palpi $(P=0.002)$. The oviposition of females without labial and maxillary palpi on substrates with conspecific tracks was lower in both consecutive tests $(P=0.002)$. Females laid $29.2 \%$ of eggs on contaminated substrates in the first test and $29.9 \%$ in the second test performed 54 months later. Oviposition on clean and contaminated substrates was similar only when antennae, labial palpi, and maxillary palpi were all ablated $(P=$ 0.846; Fig. 1A).

If palpi of only one kind were removed, the proportion of eggs laid by $C$. oculata females on contaminated substrates was similar to that of intact females (maxillary palpi, $P=0.499$; labial palpi, $P=0.531$ ). Whereas ablation of one antenna did not affect the proportion of eggs laid on contaminated substrates $(P=0.107)$, ablation of both antennae significantly reduced it relative to intact females (test 2ac, $P=0.009$; test 2a, $P=0.0001$ ). Females without labial and maxillary palpi laid a proportion of eggs on contaminated substrates similar to that of females without antennae (test $2 \mathrm{ac}, P=0.756$; test $2 \mathrm{a}, P=$ 0.202).

C. perla laid lower numbers of eggs on substrates with fresh tracks of conspecific larvae than on clean substrates after the ablation of both antennae $(P=0.002)$, one leg of

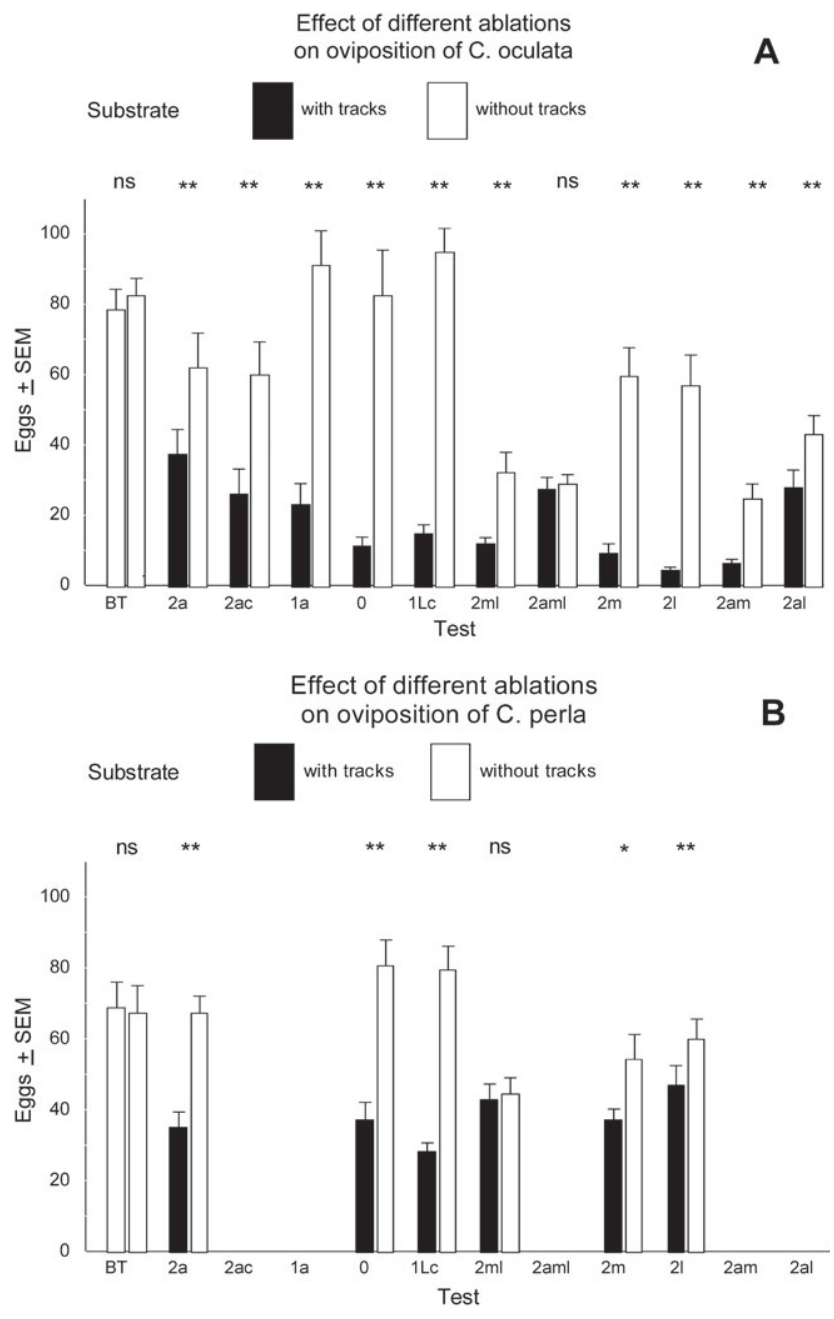

Fig. 1. Effects of different ablations on the choice of oviposition substrates by Chrysopa oculata (A) and Chrysopa perla (B). Ten females were tested in each of 10 replicates in each test. Tracks of first instars were used. Wilcoxon paired-sample test, ${ }^{* *} P<0.01 ; * P<0.05 ; \mathrm{ns}=$ not significantly different $(P$ $>0.05$ ). Details on ablations in Table 1 .

the second pair $(P=0.002)$, both labial palpi $(P=0.004)$, or both maxillary palpi $(P=0.0195)$. In contrast to $C$. oculata, $C$. perla laid similar numbers of eggs on contaminated and clean substrates when both labial palpi and maxillary palpi were removed $(P=0.557$; Fig. $1 \mathrm{~B})$. $C$. perla lacking both pairs of palpi also laid similar numbers of eggs on clean substrates and substrates with tracks of C. oculata first instars $(P=0.695)$.

\section{Persistence of larval tracks}

Females of $C$. oculata and $C$. perla laid similar numbers of eggs on each of two clean substrates in blank tests. The repellency of conspecific larval tracks persisted longer in C. oculata than in C. perla (Table 2). Although the proportion of eggs laid by $C$. oculata on contaminated substrates gradually increased over time, females laid a significantly higher proportion of eggs on clean substrates in all tests, even after 1100 days. In contrast, the preference of $C$. perla females for clean substrates over those 
TABle 2. Duration of oviposition-deterring effects of larval tracks following various periods of storage. Tracks of first instars were used.

\begin{tabular}{|c|c|c|c|c|c|c|c|c|c|c|c|c|}
\hline \multirow{3}{*}{$\begin{array}{l}\text { Oviposition } \\
\text { Larval tracks } \\
\text { Substrate }\end{array}$} & \multicolumn{6}{|c|}{ Chrysopa oculata } & \multicolumn{6}{|c|}{ Chrysopa perla } \\
\hline & \multicolumn{2}{|c|}{ Chrysopa oculata } & \multicolumn{4}{|c|}{ Chrysopa perla } & \multicolumn{2}{|c|}{ Chrysopa perla } & \multicolumn{4}{|c|}{ Chrysopa oculata } \\
\hline & clean & clean & & clean & clean & & clean & clean & & clean & clean & \\
\hline Blank test $^{\mathrm{a}}$ & $41 \pm 7$ & $45 \pm 7$ & ns & $41 \pm 7$ & $45 \pm 7$ & ns & $13 \pm 1$ & $17 \pm 2$ & $\mathrm{~ns}$ & $13 \pm 1$ & $17 \pm 2$ & ns \\
\hline Substrate & with tracks & clean & & with tracks & clean & & with tracks & clean & & with tracks & clean & \\
\hline \multicolumn{13}{|l|}{ Storage (days) } \\
\hline 0 & $4 \pm 1$ & $61 \pm 7$ & $* *$ & $9 \pm 3$ & $45 \pm 12$ & $* *$ & $6 \pm 1$ & $26 \pm 3$ & $* *$ & $9 \pm 2$ & $21 \pm 2$ & $* *$ \\
\hline 1 & $3 \pm 1$ & $61 \pm 11$ & $* *$ & $13 \pm 3$ & $40 \pm 3$ & $* *$ & $9 \pm 3$ & $35 \pm 3$ & $* *$ & $7 \pm 1$ & $29 \pm 6$ & $* *$ \\
\hline 5 & $8 \pm 2$ & $58 \pm 10$ & $* *$ & $22 \pm 7$ & $51 \pm 5$ & $* *$ & $13 \pm 1$ & $31 \pm 5$ & $* *$ & $8 \pm 2$ & $28 \pm 3$ & $* *$ \\
\hline 10 & $4 \pm 1$ & $54 \pm 10$ & $* *$ & $12 \pm 2$ & $49 \pm 6$ & $* *$ & $11 \pm 2$ & $32 \pm 7$ & $*$ & $9 \pm 2$ & $29 \pm 3$ & $* *$ \\
\hline 30 & $9 \pm 3$ & $63 \pm 11$ & $* *$ & $18 \pm 3$ & $38 \pm 9$ & $*$ & $18 \pm 5$ & $34 \pm 8$ & $* *$ & $10 \pm 4$ & $28 \pm 4$ & $* *$ \\
\hline 180 & $26 \pm 6$ & $90 \pm 11$ & $* *$ & $61 \pm 9$ & $101 \pm 9$ & $*$ & $14 \pm 2$ & $38 \pm 5$ & $* *$ & $10 \pm 1$ & $26 \pm 3$ & $* *$ \\
\hline 360 & $56 \pm 8$ & $116 \pm 12$ & $* *$ & $59 \pm 17$ & $84 \pm 20$ & $*$ & $12 \pm 2$ & $36 \pm 5$ & $* *$ & $20 \pm 4$ & $36 \pm 4$ & $* *$ \\
\hline 540 & $40 \pm 6$ & $89 \pm 14$ & $* *$ & $58 \pm 5$ & $93 \pm 20$ & ns & $21 \pm 3$ & $41 \pm 7$ & $* *$ & $27 \pm 4$ & $64 \pm 5$ & $* *$ \\
\hline 720 & $63 \pm 9$ & $89 \pm 6$ & $*$ & $64 \pm 8$ & $77 \pm 13$ & ns & $25 \pm 5$ & $30 \pm 3$ & ns & $40 \pm 5$ & $53 \pm 8$ & ns \\
\hline 1100 & $54 \pm 11$ & $77 \pm 11$ & $*$ & $60 \pm 5$ & $66 \pm 6$ & ns & $39 \pm 7$ & $58 \pm 5$ & $\mathrm{~ns}$ & $36 \pm 4$ & $57 \pm 6$ & $* *$ \\
\hline
\end{tabular}

Mean number (per replicate) \pm SEM of eggs laid by chrysopid females in choice tests. Ten replicates by each test, 10 females in one replicate. Numbers of eggs compared with Wilcoxon paired-sample tests (two-sided $P$ value): ${ }^{* *} P<0.01 ;{ }^{*} P<0.05$; ns $=$ not significantly different $(P>0.05)$. ${ }^{\text {a }}$ Two clean substrates, storage 0 days.

contaminated by conspecific first instars disappeared after 540 days of storage.

Substrates contaminated with tracks of $C$. perla lost their repellency to $C$. oculata females faster than did those of the reciprocal combination. While $C$. oculata laid fewer eggs on strips with tracks of $C$. perla larvae than on clean substrates after 360 days of storage, $C$. perla laid fewer eggs on strips with tracks of $C$. oculata larvae even after 1100 days (Table 2).

\section{Effect of larval age and solubility of ODSCs}

Females of $C$. oculata laid fewer eggs on substrates with tracks of first and third instar larvae (Mean $\pm \mathrm{SE}=4$ \pm 1.1 and $10.6 \pm 1.5$, respectively) than on simultaneously provided clean substrates $(78.6 \pm 8.1$ and $58.7 \pm 4.7$, respectively), a significant result in both tests $(P=0.002)$. On average, only $5.0 \%$ of eggs were laid on substrates contaminated by first instars, and $15.4 \%$ on substrates contaminated by third instars.

The oviposition of $C$. oculata was lower on substrates soaked with water extracts of the conspecific tracks of first instars than on clean substrates. Females laid fewer eggs on substrates soaked with fresh and with 30-day-old extracts $(0.8 \pm 0.4$ and $0.4 \pm 0.2$, respectively) than on simultaneously provided clean substrates $(9.2 \pm 2.6$ and $29.4 \pm 3.0$, respectively), both significant results $(P=$ 0.006 ). On average, females laid $9.0 \%$ of eggs on substrates contaminated with fresh water extract and $1.4 \%$ on substrates contaminated with extract stored for 30 days at $-30^{\circ} \mathrm{C}$.

C. oculata laid fewer eggs on substrates treated with fresh chloroform extract of first instars than on substrates treated with the solvent alone $(0.4 \pm 0.2$ vs $28.7 \pm 5.3, \mathrm{P}=$ $0.002)$. Females laid an average of $1.0 \pm 0.3$ eggs on substrates soaked with extract stored for 120 days in the freezer and later held for 10 days at room temperature versus $30.4 \pm 5.5$ eggs on substrates treated with solvent alone $(\mathrm{P}=0.002)$. When the chloroform extract was held for 120 days in the freezer and then 630 days at room temperature, females laid $2.8 \pm 0.8$ eggs on contaminated substrates versus $73.3 \pm 3.6$ on solvent-treated substrates $(\mathrm{P}=0.002)$. In these successive tests, $C$. oculata laid on average $2.8 \%, 3.3 \%$, and $3.8 \%$ of total eggs on contaminated substrates. In contrast, the fresh hexane extract of third instars did not deter conspecific females from laying eggs $(P=0.1055)$.

\section{DISCUSSION}

Chrysopids are not considered to be strong fliers, but some species frequently cover long distances with the help of winds. Reproductively active females do not necessarily stay in one field even when plenty of food is available. The dispersal tendency of chrysopids has been described as a continuous "downwind nomadism" (Duelli, 1984). Whereas this process may be largely passive, olfactory orientation to volatiles emanating from prey or artificial attractants appears to play an important role in the selection of landing sites (Duelli, 1980).

An ability of chrysopid females to detect volatile ODSC components via their antennae could enable them to respond to the presence of chrysopid larvae during flight and thus affect their selection of landing sites. Substrates exposed for $4 \mathrm{~h}$ to a volatile ODSC from fresh tracks of $C$. oculata first instars deterred conspecific females from ovipositing, indicating females can respond to volatile ODSC components. While substrates contaminated with volatiles from tracks of $C$. oculata larvae deterred conspecific females for only a few days, those actually contacted by larvae retained their deterrent effects for weeks. Tracks of first instars deter oviposition even after exposure to $140^{\circ} \mathrm{C}$ for one hour (Růžička, 1997a), indicating considerable thermal stability of the compound. After landing, females obviously respond to 
more persistent semiochemical residues, probably through palpation like coccinellids (Růžička, 2003).

Detection of ODSCs through individual pairs of sense organs was more complex in $C$. oculata than in $C$. perla. C. oculata females failed to differentiate clean from contaminated substrates solely when deprived of antennae and both kinds of palpi. The ablation of maxillary palpi had no significant effect on the preference for clean substrates over contaminated ones. Likewise, the ability of females deprived of labial palpi to prefer clean substrates was similar to that of intact females. Females retained the ability to detect conspecific ODSCs, apparently via the antennae, even after ablation of both pairs of palpi. The behaviour of females with only antennae did not differ from that of females deprived solely of antennae. These results demonstrate redundant perception of ODSC's via multiple sensory structures.

In contrast to $C$. oculata, $C$. perla females did not respond to ODSCs via antennae when both pairs of palpi were removed. After ablation of only one kind of palpi, females always laid significantly fewer eggs on contaminated substrates, indicating that palpi of each kind bear sensillae capable of detecting conspecific tracks. Tracks of first instar C. oculata deterred C. perla females from oviposition more than did tracks of conspecific first instars (Růžička, 1998). One may speculate whether this was due to a quantitative effect (a higher amount of deterrent substance in tracks of $C$. oculata larvae) or a qualitative one (a different compound with stronger activity). $C$. perla lacking both kinds of palpi also laid similar numbers of eggs on substrates with tracks of $C$. oculata larvae as on clean substrates, indicating an inability to use the antennae to detect even the stronger ODSC of heterospecific larvae.

Experiments with females deprived of one leg of the second pair showed the excellent capability of $C$. oculata and $C$. perla to discriminate between clean and contaminated substrates after severe injury and by decreased mobility. Similarly, ablation of one leg of the second pair had no significant effect on the degree of preference for clean substrates by females of aphidophagous coccinellids C. limbifer and C. undecimnotata (Růžička, 2003).

Although females have no receptive sensillae on their legs, tarsi apparently play a certain role in ODSC detection. Females likely contaminate tarsal segments with ODSCs and other semiochemicals during walking on the plant surface. Since both aphidophagous chrysopids and coccinellids frequently clean the tarsi of the first pair of legs with the mouthparts, this cleaning behaviour is likely to transfer semiochemicals from tarsi to gustatory sensory organs and thus enhance detection of conspecific and heterospecific tracks.

Although females of both $C$. oculata and C. perla responded to tracks of conspecific larvae, the response of the latter species was considerably lower, corresponding with previous findings (Růžička, 1996, 1998). In laboratory rearing and experiments, $C$. oculata frequently lays eggs in rows closely spaced, whereas $C$. perla usually lays single eggs with greater distance between them. Pre- sumably, neonate larvae of $C$. oculata would encounter higher densities of conspecifics than those of $C$. perla. Whether the intensity of response to larval tracks is related to a species-specific propensity for cannibalism remains to be tested. Substrates contaminated by $C$. oculata larvae remained deterrent to females of both species considerably longer than those contaminated by $C$. perla larvae, in accordance with stronger initial deterrency. These results suggest that ODSC may persist for considerable periods on plants in nature under favourable conditions. Oviposition in experiments with conspecific and heterospecific tracks generally increased with time of storage on contaminated substrates as well as on clean substrates, though less on the latter, indicating overall gradual decrease of deterrency of tracks on oviposition inside cages.

The deterrent effects of tracks of first and third instars were surprisingly similar, in accordance with preliminary results on ODSCs in tracks of chrysopid larvae (Růžička, 1994). It remains unclear, however, why third instars cause less contamination of substrates with ODSCs than first instars. Numbers of eggs laid by the coccinellid Adalia bipunctata (L.) also did not differ among Petri dishes previously containing an excess of aphids and either first, second, third, or fourth conspecific instars (Doumbia et al., 1998). However, although the fresh tracks of first and second instar Coccinella septempunctata had strong oviposition-deterring effects, only tracks of the second instars deterred conspecific females from ovipositing after $24 \mathrm{~h}$ (Růžička, 1997b). Similarly, $C$. oculata females responded more to substrates with tracks of older instars of the coccinellid Coleomegilla maculata lengi Timberlake than to those of younger ones (Chauhan \& Weber, 2008).

The water extract of tracks of $C$. oculata first instars deterred conspecific females from oviposition. Fresh extract and extract stored for one month in a freezer deterred females similarly. The solubility of ODSCs in water and effects of weathering factors such as solar radiation could thus potentially diminish the persistence of larval tracks on plants in the field.

Substrates treated with chloroform extract of C. oculata larvae had an extremely strong deterrent effect on oviposition by conspecific females. This extract could potentially be exploited in the rearing of chrysopids, especially in their mass production for biological control programmes. If coated with chloroform extract, constructional parts of breeding cages would effectively repel females and promote egg laying on exchangeable substrates provided specifically for oviposition.

In coccinellids, fresh tracks of $C$. limbifer larvae exhibited strong oviposition-deterrence for conspecific females (Růžička, 2001a, 2003) and also repelled conspecific larvae (Růžička \& Zemek, 2008), but simultaneously prolonged the residence time of conspecific females on sites with tracks (Růžička \& Zemek, 2003). In contrast, fresh tracks of larvae of the coccinellid $C$. undecimnotata had the opposite effect on the residence time of $C$. limbifer females, although they also deterred oviposition 
(Růžička, 2001a, 2003). Whether chrysopid larval tracks also deter conspecific larvae or influence searching behaviour of chrysopid females should be investigated.

In conclusion, females of aphidophagous chrysopids employ multiple sense organs for detection of ODSCs in tracks of conspecific larvae, and these organs are all located on the head. Interestingly, the role of antennae was species-specific. Whereas only palpi were involved in the detection of ODSCs by C. perla, C. oculata could detect them via the antennae. Choice tests indicate an absence of sensillae for ODSC detection on tarsi or other parts of the body in both species. Further research is needed to confirm the perception of volatile ODSC components by $C$. oculata via antennae during nomadic flight, but some volatility of ODSC components is evident. Chloroform extracts of ODSCs are easy to collect and retain persistence for long periods of storage, rendering them potentially useful for manipulation of oviposition in the mass-rearing of chrysopid species.

ACKNOWLEDGEMENTS. This research was supported by the grant project S5007102 (Grant Agency Acad. Sci. CR) and from the Entomology Institute project Z5007907 (Acad. Sci. CR). I thank M. Červenská, R. Guttwirthová and V. Malhocká for their assistance with the experiments and insect cultures. I am grateful to two anonymous reviewers for constructive criticism and helpful comments on the manuscript.

\section{REFERENCES}

Anbutsu H. \& Togashi K. 2000: Deterred oviposition response of Monochamus alternatus (Coleoptera, Cerambycidae) to oviposition scars occupied by eggs. Agric. Forest Entomol. 2: 217-223.

Anbutsu H. \& Togashi K. 2001: Oviposition deterrent by female reproductive gland secretion in the Japanese pine sawyer, Monochamus alternatus. J. Chem. Ecol. 27: 1151-1161.

Bitsch J. 1984: Anatomy of adult Chrysopidae. In Canard M., Séméria Y. \& New T.R. (eds): Biology of Chrysopidae. Dr. W. Junk, The Hague, pp. 29-36.

Benuzzi M., Manzaroli G. \& Mosti M. 1991: Lotta biologica e integrata sulla fragola. Frutticoltura 9: 63-67.

Boo K.S., Chung I.B., Han K.S., Pickett J.A. \& Wadhams L.J. 1998: Response of the lacewing Chrysopa cognata to pheromones of its aphid prey. J. Chem. Ecol. 24: 631-643.

Chauhan K.R. \& Weber D.C. 2008: Lady beetle (Coleoptera: Coccinellidae) tracks deter oviposition by the goldeneyed lacewing, Chrysopa oculata. Biocontrol Sci. Technol. 18: 727-731.

Chauhan K.R., Zhang Q.H. \& Aldrich J.R. 2004: Iridodials: enantiospecific synthesis and stereochemical assignment of the pheromone for the golden-eyed lacewing, Chrysopa oculata. Tetrahedron Lett. 45: 3339-3340.

Chauhan K.R., Levi V., Zhang Q.-H. \& Aldrich J.R. 2007: Female goldeneyed lacewings (Neuroptera: Chrysopidae) approach but seldom enter traps baited with the maleproduced compound iridodial. J. Econ. Entomol. 100: $1751-1755$.

Doumbia M., Hemptinne J.-L. \& Dixon A.F.G. 1998: Assessment of patch quality by ladybirds: role of larval tracks. Oecologia 113: 197-202.

Duelli P. 1980: Adaptive dispersal and appetitive flight in the green lacewing, Chrysopa carnea. Ecol. Entomol. 5: 213-220.
Duelli P. 1984: Dispersal and oviposition strategies in Chrysoperla carnea. In Gepp J., Aspöck H. \& Hölzel H. (eds): Progress in World's Neuropterology. Proc. I. Int. Symp. on Neuropterology. Thalerhof, Graz, pp. 133-146.

Ferguson A.W., Ziesmann J., Blight M.M., Williams I.H., Wadhams L.J., Clark S.J., Woodcock C.M. \& Mudd A. 1999: Perceptiom of oviposition deterring pheromone by cabbage weevil (Ceutorhynchus assimilis). J. Chem. Ecol. 25: $1655-1670$.

Fréchette B., Coderre D. \& Lucas E. 2006: Chrysoperla rufilabris (Neuroptera: Chrysopidae) females do not avoid ovipositing in the presence of conspecific eggs. Biol. Control 37: 354-358.

HAGEN K.S. 1986: Ecosystem analysis: plant cultivars (HPR), entomophagous species and food supplements. In Boethel D.J. \& Eikenbary R.D. (eds): Interactions of Plant Resistance and Parasitoids and Predators of Insects. Wiley, New York, pp. 151-197.

HAGEN K.S. \& TASSAN R.L. 1966: The influence of protein hydrolysate of yeasts and chemically defined diets upon the fecundity of Chrysopa carnea Stephens (Neuroptera). Věst. Čs. Spol. Zool. 30: 219-227.

HAN B.Y. \& CHEN Z.M. 2002a: Composition of the volatiles from intact and tea-damaged tea shoots and their allurement to several natural enemies of the tea aphid. J. Appl. Entomol. 126: $497-500$.

HAN B.Y. \& ChEN Z.M. 2002b: Behavioral and electrophysiological responses of natural enemies to synomones from tea shoots and kairomones from tea aphids, Toxoptera aurantii. $J$. Chem. Ecol. 28: 2203-2219.

HoKkANEN H.M.T. 1997: Role of biological control and transgenic crops in reducing use of chemical pesticides for crop protection. In Pimentel D. (ed.): Techniques for Reducing Pesticide Use. Wiley, New York, pp. 103-127.

Hooper A.M., Donato B., Woodcock C.M., Park J.H., Paul R.L., Boo K.S., Hardie J. \& Pickett J.A. 2002: Characterization of $(1 \mathrm{R}, 4 \mathrm{~S}, 4 \mathrm{aR}, 7 \mathrm{~S}, 7 \mathrm{aR})$-dihydronepetalactol as semiochemical for lacewings, including Chrysopa spp. and Peyerimhoffina gracilis. J. Chem. Ecol. 28: 849-864.

Hurter J., Katsoyannos B., Bollor E.F. \& Wirz P. 1976: Beitrag zur Anreicherung und Teilweisen Reinigung der eiablageverhindernden Pheromons der Kirschenfliege, Rhagoletis cerasi L. (Dipt., Trypetidae). Z. Angew. Entomol. 80: 50-56.

Klijustra J.W. \& Roesingh P. 1986: Perception of the oviposition-deterring pheromone by tarsal and abdominal contact chemoreceptors in Pieris brassicae. Entomol. Exp. Appl. 40: 71-79.

Laubertie E., Martini X., Cadena C., Treilhou M., Dixon A.F.G. \& Hemptinne J.L. 2006: The immediate source of the oviposition-deterring pheromone produced by larvae of Adalia bipunctata (L.) (Coleoptera, Coccinellidae). J. Insect Behav. 19: 231-240.

McEwen P.K., New T.R. \& WhitTington A.E. 2001: Lacewings in the Crop Management. Cambridge University Press, Cambridge, $546 \mathrm{pp}$.

Ravensberg W.J. 1992: Production and utilization of natural enemies in western European glasshouse crops. In Anderson T.E. \& Leppla N.C. (eds): Advances in Insect Rearing for Research and Pest Management. Westview Press, Boulder, CO, pp. 465-487.

REDDY G.V.P. 2002: Plant volatiles mediate orientation and plant preference by the predator Chrysoperla carnea Stephens (Neuroptera: Chrysopidae). Biol. Control 25: 49-55.

Reddy G.V.P., Holopainen J.K. \& Guerrero A. 2002: Olfactory responses of Plutella xylostella natural enemies to host phero- 
mone, larval frass, and green leaf cabbage volatiles. J. Chem. Ecol. 28: 131-143.

Reddy G.V.P., Tabone E. \& Smith M.T. 2004: Mediation of host selection and oviposition behaviour in the diamondback moth Plutella xylostella and its predator Chrysoperla carnea by chemical cues from cole crops. Biol. Control 29: 270-277.

RIDGWAY R.L. \& JONES S.L. 1969: Inundative releases of Chrysopa carnea for control of Heliothis on cotton. J. Econ. Entomol. 62: 177-180.

RŮŽIČKA Z. 1994: Oviposition deterring pheromone in Chrysopa oculata (Neuroptera: Chrysopidae). Eur. J. Entomol. 91: 361-370.

RŮŽIČKA Z. 1996: Oviposition-deterring pheromone in Chrysopidae (Neuroptera): Intra- and interspecific effects. Eur. J. Entomol. 93: 161-166.

RŮŽIČKA Z. 1997a: Persistence of the oviposition-deterring pheromone in Chrysopa oculata (Neur.: Chrysopidae). Entomophaga 42: 109-114.

RŮžIČKA Z. 1997b: Recognition of oviposition-deterring allomones by aphidophagous predators (Neuroptera: Chrysopidae, Coleoptera: Coccinellidae). Eur. J. Entomol. 94: 431-434.

RŮŽIČKA Z. 1998: Further evidence of oviposition-deterring allomone in chrysopids (Neuroptera: Chrysopidae). Eur. J. Entomol. 95: 35-39.

RŮŽIČKA Z. 2001a: Oviposition responses of aphidophagous coccinellids to tracks of coccinellid (Coccinellidae) and chrysopid (Chrysopidae) larvae. Eur. J. Entomol. 98: 183-188.

RŮŽIČKA Z. 2001b: Response of chrysopids (Neuroptera) to larval tracks of aphidophagous coccinellids (Coleoptera). Eur. J. Entomol. 98: 283-285.

RŮŽIČKA Z. 2003: Perception of oviposition-deterring track in aphidophagous coccinellids Cycloneda limbifer and Ceratomegilla undecimnotata (Coleoptera: Coccinellidae). Eur. J. Entomol. 100: 345-350.

RŮŽıČKA Z. \& HAVELKA J. 1998: Effects of oviposition-deterring pheromone and allomones on Aphidoletes aphidimyza (Diptera: Cecidomyiidae). Eur. J. Entomol. 95: 211-216.

RŮŽIČKA Z. \& ZEMEK R. 2003: Effect of conspecific and heterospecific larval tracks on mobility and searching patterns of Cycloneda limbifer Say (Coleoptera: Coccinellidae) females. In Soares A.O., Ventura M.A., Garcia V. \& Hemptinne J.-L. (eds): Biology, Ecology and Behaviour of Aphidophagous Insects. Proc. 8th Int. Symp. Ecology of Aphidophaga. Arquipélago. Life and Marine Sciences. Suppl. 5, pp. 85-93.
RŮŽIČKA Z. \& ZEMEK R. 2008: Deterrent effects of larval tracks on conspecific larvae in Cycloneda limbifer. BioControl 53: 763-771.

Schoonhoven L.M. 1990: Host marking pheromones in Lepidoptera with special reference to two Pieris spp. J. Chem. Ecol. 16: 3043-3052.

Senior L.J. \& McEwen P.K. 2001: The use of lacewings in biological control. In McEwen P.K., New T.R. \& Whittington A.E. (eds): Lacewings in the Crop Management. Cambridge University Press, Cambridge, pp. 296-302.

Städler E., Ernst B., Hurter J. \& Boller E. 1994: Tarsal contact chemoreceptor for the host marking pheromone of the cherry fruit fly, Rhagoletis cerasi: responses to natural and synthetic compounds. Physiol. Entomol. 19: 139-151.

VAN EMDEN H.F. \& HAGEN K.S. 1976: Olfactory reactions of green lacewing, Chrysopa carnea, to tryptophan and certain breakdown products (Neuroptera, Chrysopidae). Environ. Entomol. 5: 469-473.

VAN Lenteren J.C. 1972: Contact chemoreceptors on the ovipositor of Pseudocoila bochei Weld (Cynipidae). Neth. J. Zool. 22: 347-350.

Zhang Q.H., Chauhan K.R., Erbe E.F., Vellore A.R. \& AldRICH J.R. 2004: Semiochemistry of the goldeneyed lacewing Chrysopa oculata: Attraction of males to a male-produced pheromone. J. Chem. Ecol. 30: 1849-1870.

Zhang Q.H., Sheng M.L., Chen G.F., Aldrich J.R. \& Chauhan K.R. 2006: Iridodial: a powerful attractant for the lacewing Chrysopa septempunctata (Neuroptera: Chrysopidae). Naturwissenschaften 93: 461-465.

Zhu J., Cossé A.A., OBrycki J.J., Boo K.S. \& BAKer T.C. 1999: Olfactory reactions of the twelve-spotted lady beetle Coleomegilla maculata and the green lacewing, Chrysoperla carnea to semiochemical released from their prey and host plant: electroantennogram and behavioral responses. J. Chem. Ecol. 25: 1163-1177.

Zhu J., Unelius R.C., Park K.C., Ochieng S.A., Obrycki J.J. \& BAKER T.C. 2000: Identification of (Z)-4-tridecene from defensive secretion of green lacewing, Chrysoperla carnea. $J$. Chem. Ecol. 26: 2421-2434.

Zhu J., Obrycki J.J., Ochieng S.A. Baker T.C., Pickett J.A. \& SMILEY D. 2005: Attraction of two lacewing species to volatiles produced by host plants and aphid prey. Naturwissenschaften 92: 277-281.

Received June 30, 2009; revised and accepted November 2, 2009 